saluretic action. This effect could be explained by alterations of renal haemodynamics - that is, to be due to the rise of renal plasma flow and filtration rate, resulting in the changes of water and salt reabsorption. This possibility is not in the least excluded by the fact that the rise in glomerular filtration and renal plasma flow was much less than that in water and sodium excretion. Against this view, however, stands the fact that the changes in glomerular filtration and plasma flow were not always followed by similar changes in water and sodium excretion. It is to be noted in our experiments that out of 45 post-chlorpromazine clearance periods water excretion rose considerably in 11 cases, and sodium excretion in 7 , in spite of a significant fall in glomerular filtration rate and renal plasma flow.

In six normal persons chlorpromazine had no consistent effect on renal function. Diuresis increased in three cases, decreased in two, and in one was unaltered. Glomerular filtration decreased in three cases, and showed no change in the other three. The renal plasma flow diminished in three cases. was unchanged in one, and showed a slight but inconsiderable rise in the other two. Sodium excretion decreased in two cases, and did not alter in three.

Our results will be communicated in detail in the Acta Medica Academiae Scientiarum Hungaricae.

\section{PERICARDITIS AND ELECTROCARDIOGRAPHIC CHANGES IN REITER'S SYNDROME}

BY

G. W. CSONKA, M.D., M.R.C.P.

Consultant Venereologist, Addenbrooke's Hospital, Cambridge

AND

J. K. OATES, M.B., M.R.C.P.Ed.

Physician to M.R.C. Investigation of Non-specific Urethritis

Reiter's syndrome is a condition which has been known for many years, but has been studied in detail only during the last ten to fifteen years. It presents with nongonococcal urethritis, polyarthritis, conjunctivitis, and sometimes iritis, a characteristic balanitis, or eruption on the skin (keratoderma blennorrhagica), and the syndrome may show all these features or only two or three.

Several authors have described evidence suggesting cardiac involvement in the course of these infections, but, as one would expect with a non-fatal condition most commonly affecting young people, post-mortem evidence is lacking.

Electrocardiographic changes suggesting myocarditis were reported by Gadrat and Morrell (1935), Bang (1940), Candel and Wheelock (1945), Feiring (1946), Paronen (1948), Lövgren and Masreliez (1949), Trier (1950), Shapiro et al. (1949), and Weinberger et al. (1952). Paronen also recorded seven cases which developed pericarditis with an audible friction rub out of a total of 308 patients suffering from the syndrome. Lever and Crawford (1944) recorded a case of a 35-yearold man who, during the fourth month of a severe attack of Reiter's disease, complained of substernal oppression and whose electrocardiogram showed changes suggestive of recent myocardial infarction. An electrocardiogram earlier in the attack had been normal. He died four days later, but a post-mortem examination was not carried out.

Mayne (1955) described a case of Reiter's syndrome with electrocardiographic changes suggesting pericarditis which at the time of publication had persisted unaltered over the unusually long period of 15 months. He also recorded a further case of a man aged 30 with Reiter's syndrome who had electrocardiographic changes strongly suggestive of anterior myocardial infarction. Neither of these patients had any symptoms of cardiac disease.

\section{Present Series}

In 128 cases of complete Reiter's syndrome, mostly in men between 20 and 35 years of age, clinical evidence of heart disease developed during the attack in only two patients, both of whom suffered from pericarditis. Six patients had complained of transient chest pain, which was thought at the time. to be due to connective-tissue involvement. In view of our later experience it is possible that some of these patients may also have had pericarditis.

E le ct r o cardiography now forms a routine part of our investigation of all patients with Reiter's syndrome and 4 out of 25 cases have shown abnormal tracings. The case histories of these four patients illustrate some of the cardiological abnormalities which may be found in Reiter's syndrome.

\section{Case 1}

On admission to hospital a West Indian man aged 38 gave a history of urethral discharge and polyarthritis for a month. His urethral infection had been treated originally by his own doctor with a course of a sulphonamide, but recurred two weeks later, together with terminal haematuria. Many joints of both arms and legs were involved, and there was also pain in the lumbar region and marked plantar fasciitis and swelling of the Achilles tendons. For the first week

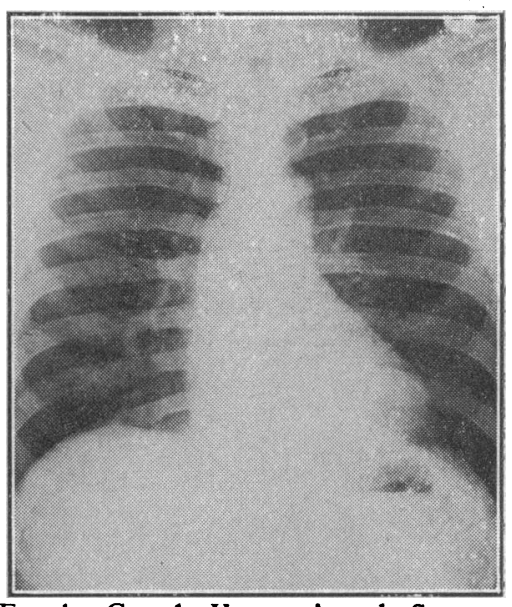

Fig. 1.-Case 1. Heart enlarged. Screening showed this to be of left ventricular origin.

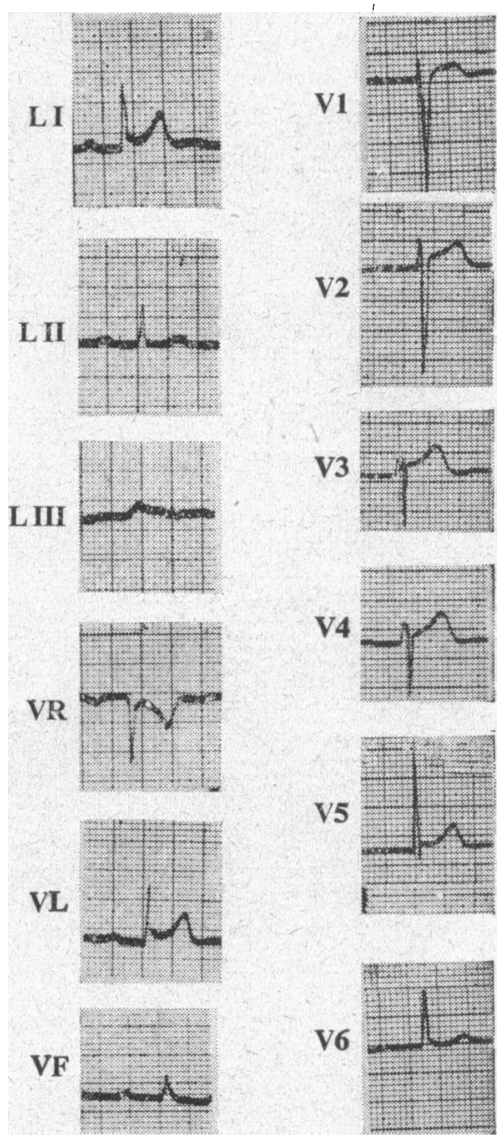

Fig. 2.-Case 1. Prolonged P-R interval of 0.28 second and ST elevation in $\mathrm{L} I, \mathrm{VL}, \mathrm{V} 1, \mathrm{~V} 2, \mathrm{~V} 3$, and 
there was a slight pyrexia of up to $100^{\circ} \mathrm{F} .\left(37.8^{\circ} \mathrm{C}.\right)$. The patient complained of transient central chest pain soon after admission, but on clinical examination no cause for this was detected. Treatment with salicylates and bed rest

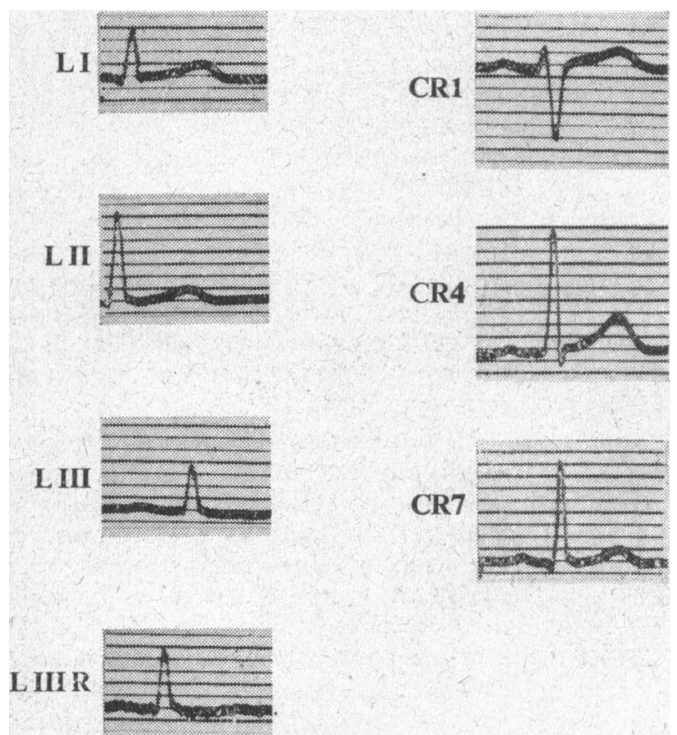

Fig. 3.-Case 2, Elevation of ST segment in L I, L II, and CR leads.

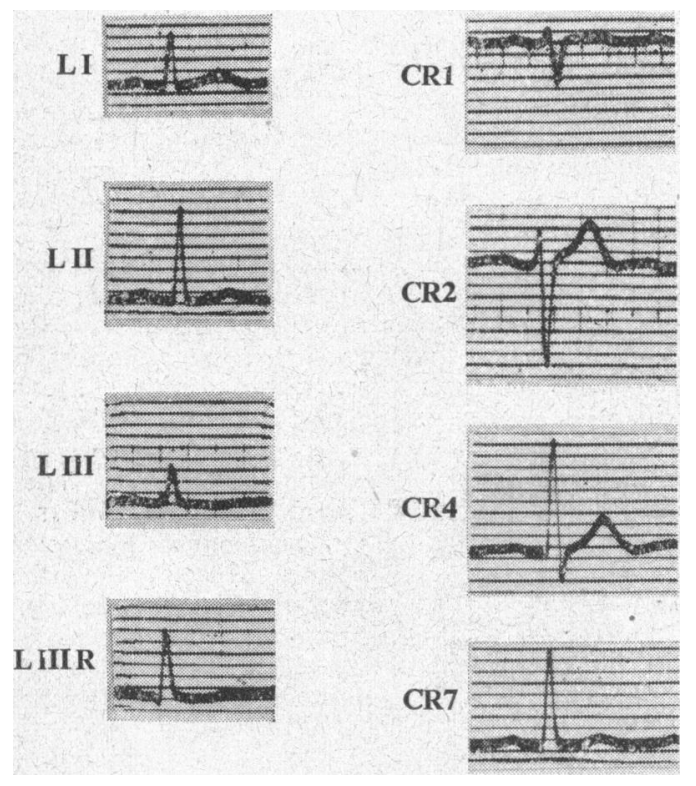

FIg. 4.-Case 2. ST elevation much less marked in L I, CR4, and CR7.

did not improve his condition, and fever therapy with intravenous $E$. coli vaccine was tried. After three injections there was considerable symptomatic improvement and he was discharged from hospital.

He had contracted gonorrhoea eight years previously, and this was followed by the development of a urethral stricture. He gave no history of rheumatic fever or previous joint or heart disease. The Wassermann and Kahn reactions were negative and the gonococcal fixation test was strongly positive. The E.S.R. was $80 \mathrm{~mm}$. in one hour, haemoglobin $106 \%$, white blood cells 5,250 , with $57 \%$ polymorphonuclear leucocytes. A mid-stream specimen of urine showed a few pus cells and was sterile. $X$-ray examination of the chest showed the heart to be enlarged, with some prominence in the region of the left ventricle (Fig. 1). The affected joints showed no abnormality. The blood pressure was $150 / 100$.

After leaving hospital he had intermittent pain in various joints and was readmitted with renewed swelling of the same joints as on the first occasion and also of the right elbow. Slight urethral discharge was present, and microscopically showed polymorphonuclear leucocytes and red blood cells but no gonococci. The prostatic secretions contained a considerable excess of polymorphonuclear leucocytes. He developed a mild symptomless bilateral conjunctivitis, which subsided in a few days. A routine electrocardiogram taken on the same day (Fig. 2) showed a prolonged $P-R$ interval of 0.28 second and ST elevation in leads I, VL, V1, V2, V3, and V4. Radiographs of the heart were similar to the previous film, and screening gave no additional information. Nine days later he complained again of central substernal pain, which continued for two days. During this time a pericardial friction rub was heard, but the electrocardiographic tracing showed no change. His joints improved slowly and he was discharged three weeks later. Further electrocardiograms were taken at monthly intervals, but these still showed no change. He was well enough to start work again, and the only abnormality found on clinical examination was minimal stiffness in the knees and several fingers, together with the evidence of chronic prostatic infection.

\section{Case 2}

A man aged 24 was admitted to hospital complaining of thick urethral discharge, of soreness of both eyes, and pain in the left heel for one week. He denied sexual intercourse. Polyarthritis developed and affected both knees, ankles, left shoulder, several metacarpophalangeal and proximal interphalangeal joints, and the second, third, and fourth metatarsophalangeal joints of both feet. His illness lasted approximately 14 weeks, and during this time he also suffered two attacks of conjunctivitis and two of iridocyclitis. Lesions of keratoderma blennorrhagica appeared on the palms, soles, genitalia, and limbs.

For the first 14 days he had intermittent pyrexia of up to $100^{\circ} \mathrm{F}$. $\left(37.8^{\circ} \mathrm{C}\right.$.). For the next six weeks he ran fever of up to $101^{\circ} \mathrm{F}$. $\left(38.3^{\circ} \mathrm{C}\right.$.) in the evenings, falling to $99.5^{\circ} \mathrm{F}$. $\left(37.5^{\circ} \mathrm{C}\right.$ ) in the mornings. He complained on several occasions of attacks of pain in the chest. Throughout the course of his 14-weeks stay in hospital he showed tachycardia of 95 to 115 beats a minute. No other abnormal physical signs were detected in the cardiovascular system on clinical examination. An electrocardiogram taken 10 weeks after admission showed slight elevation of the ST segment in leads I, II, CR1, CR4, and CR7 (Fig. 3). A tracing taken 10 days later showed much less ST elevation in leads I, CR4, and CR7 (Fig. 4). $X$-ray examination of the chest showed nothing abnormal. The E.S.R. was $100 \mathrm{~mm}$. in one hour, falling to $40 \mathrm{~mm}$. shortly before discharge.

\section{Case 3}

$A^{\circ}$ man aged 33 (a patient of Dr. D. Lewes) had suffered an attack of Reiter's syndrome for some two to three months, the only residual finding being the presence of bilateral calcaneal spurs. Eleven months later he suffered a further attack, this being characterized by joint pains, conjunctivitis, and a transient macular rash. He ran a fever of up to $100^{\circ} \mathrm{F}$. $\left(37.8^{\circ} \mathrm{C}\right.$.). He also complained of pain in the chest, and on examination was found to have a pericardial friction rub. The electrocardiogram showed ST elevation in leads I, II, V1, and V2 (Fig. 5). The chest $x$-ray picture was normal.

During the next seven days his fever settled and the pericardial rub disappeared. A further electrocardiogram taken 13 days later (Fig. 6) showed the $T$ wave to be flat in lead II and very low in leads I and III. 

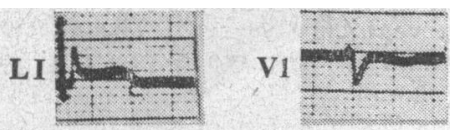

LI

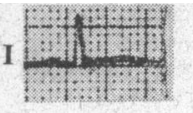

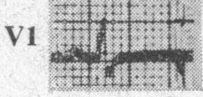
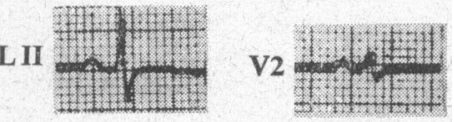

LI
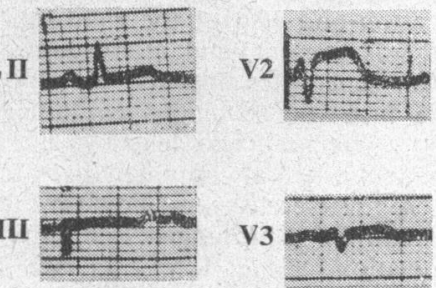

VR

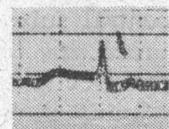

V4

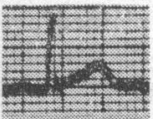

$\mathbf{V L}$
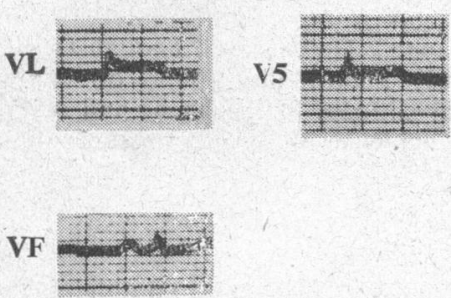

FIG. 5.-Case 3. RT deviation in L I, L II, $\dot{V} 1$, and $\dot{V} 2$, with reciprocal $S T$ depression.

Case 4

A 33-year-old man complained of dysuria, frequency, and haematuria 21 days after sexual intercourse. There were no ocular or arthritic symptoms. Shortly after admission he had a rigor and his temperature rose to $102^{\circ} \mathrm{F}$. $\left(38.9^{\circ} \mathrm{C}\right.$.). There was diffuse tenderness in the hypogastric region, and the urine contained many polymorphonuclear leucocytes and red blood cells. No organisms were seen. Clinical examination of the cardiovascular system showed no abnormality and the $x$-ray picture of the chest was normal. Three specimens of urine were cultured, but no organisms were grown. An intravenous pyelogram showed no abnormality. On receiving treatment with oxytetracycline he improved rapidly.

An electrocardiogram taken on the fourteenth day of the illness showed the following changes: slight ST elevation in leads II, III, IIIR, and CR7 (Fig. 7). When repeated two weeks later the tracing showed inversion of the $T$ wave in leads II, III, IIIR, and CR7 (Fig. 8). The patient now had no symptoms of any kind, and his urine was normal macroscopically and microscopically.

\section{Discussion}

From a study of the present series of patients and the literature it appears that clinically obvious cardiac involvement is uncommon in Reiter's syndrome, but electrocardiographic changes may be more frequent. Most of the previously reported cases have been of this nature, and overt pericarditis with an audible friction rub appears to have been reported only by Paronen (1948).

Case 4 was not characteristic of Reiter's syndrome, but of acute urinary infection of unknown aetiology following sexual exposure. As cultures and microscopy of the urine failed to demonstrate the presence of micro-organisms, it must be classified as a case of abacterial pyuria. Wellmarked electrocardiographic changes suggestive of pericarditis developed. It may be that this type of genital infection is caused by the aetiological agent which is responsible for Reiter's syndrome, as suggested by Harkness (1950). Moreover, abacterial pyuria is sometimes closely associated with a typical attack of the syndrome. No reference to the development of electrocardiographic changes in abacterial pyuria has been found in the literature.

In Case 1 the condition was thought to be rheumatoid arthritis at the time of the patient's first discharge from hospital. Arthritis following genital infection and classical rheumatoid arthritis are dissimilar in many respects, but it seems clear that both may cause cardiac involvement. Sokoloff (1953) showed, in a study of 101 post-mortem examinations of patients with rheumatoid arthritis, that pericarditis was a very common finding and that the diagnosis of pericardial disease had rarely been made during the lifetime of the patients. His figures for pericarditis for which no cause other than rheumatoid arthritis could be found were $24.8 \%$ of 101 cases, as against $2.2 \%$ of 1,154 controls. There are no post-mortem studies of Reiter's syndrome comparable to those in rheumatoid arthritis, but findings in the present series and those described in the literature suggest that low-grade pericardial involvement is not at all uncommon and may be clinically silent.

In view of this evidence there is a good case for employing electrocardiography and careful cardiac assessment as a routine in the investigation of Reiter's syndrome, and attention is also drawn to the possibility that pain in the chest may occasionally be due to pericardial involvement, a fact which is likely to be obscured by the widespread aches and pains which are characteristic of the syndrome. An unusual feature was the persistence of the electrocardiographic changes for six months in Case 1 ; this tallies with Mayne's experience, for his patient had shown unchanged electrocardiographic tracings for
FIG. 7.-Case 4. ST elevation in LII,

L III, L IIIR, and CR7. ST depression in $\mathbf{L} \mathbf{I}$.
FIG. 8.- Case 4. S wave in CR1 with ST elevation and inversion of $T$ wave. Slight $S T$

elevation with $T$ wave inversion in L II and
L III. T wave inverted in LIIIR and CR7. 
at least 15 months up to the time of writing. The remote possibility that constrictive pericarditis may develop later must be borne in mind.

\section{Summary}

Three cases of pericardial involvement in Reiter's syndrome are described.

The symptoms of this complication are not always prominent, and for this reason electrocardiography should be a routine procedure in cases of Reiter's syndrome.

A case of abacterial pyuria with pericarditis is also reported.

This work was undertaken as part of the M.R.C. research on non-specific urethritis with a grant-in-aid from the National Institute of Health of the United States Public Health Service Contract No. E652. We thank Dr. C. Young, of St. Mary's Hospital, and Dr. David Lewes, of Bedford General Hospital, for permission to study their patients, and Dr. William Evans, Mr. A. J. King, Dr. G. L. M. McElligott, and Dr. Wallace Brigden for their valuable help.

REFERENCES

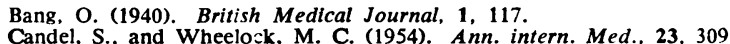

Candel, S., and Wheelock, M. C. (198.

Feiring, W. (1946). Ibid., 25, 498. Bull. Soc. franc. Derm. Syph., 42, 1849 Gadrat, J., and Morel, L. (1935). Bull. Soc. franc. Derm. Syph., 42, 1849.
Harkness, A. H. (1950). Non-Gonococcal Urethritis. Livingstone, Edinlarkness,

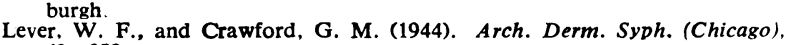
$49,389$.

Lövgren, O.. and Masreliez, N. (1949). Nord. Med., 42, 1299.

Mayne, G. O. (1955). Brit. J. vener. Dis., 31, 238.

Maronen, I. (1948). Acta med. scand., Suppl. 212

Shapiro, E., Lipkis, M. L., Kahn, J., and Heid, J. B. (1949). Amer. J. med. Sci., 217, 300 .

Sokoloff, L. (1953). Amer. Heart J., 45, 635.

Trier, M. (1950). Acta med. scand., 138, Suppl. 239, p. 123.
Weinberger, H. J., Dienes, L., and Bauer, W. (1952). In American Rheumatism Association's.' Rheumatic Diseases, Philadelphia.

\section{Medical Memorandum}

\section{Strangulation of Umbilical Hernia in Children}

The infantile type of umbilical hernia is rightly regarded as a benign condition and complications are very rare. A few cases of spontaneous rupture have been reported (MacLean, 1950 ; Strange, 1956), but strangulation of bowel in such a hernia is even more uncommon. Indeed, Browne (1952) wrote that he was unable to find a record of such an occurrence, and Woods (1953) could find no case in the records of the Bristol hospitals.

I have been able to find only two reports of strangulated umbilical hernia in children. Miller (1932) included one child of 2 years of age in his series of 60 cases of strangulated umbilical hernia seen at the Massachusetts General Hospital from 1911 to 1930 ; and Crump (1952), in his series of 329 cases of umbilical hernia in American Negro children, mentioned a case of strangulation in a 17 -monthsold girl.

Two cases of strangulated umbilical hernia have been seen at this hospital during the last six years, and in view of the rarity of the condition a brief report is considered justified.

\section{CASE 1}

A boy was admitted to hospital with oedema and albuminuria when he was 2 years old. He was found to be suffering from the nephrotic syndrome. Soon after admission he developed gross ascites, and the presence of a large umbilical hernia was recorded in the case notes. During the next two years numerous abdominal paracenteses were necessary to relieve the distress caused by large accumulations of fluid in the peritoneal cavity. He never showed evidence of renal insufficiency.

When he was 4 years old he was readmitted to hospital with a two-days history of abdominal pain and vomiting.
Examination showed that the umbilical hernia, which had previously been easily reducible, was hard and could no longer be reduced. Apart from some oedema his general condition was good, although he was noticed to have muscuiar twitchings. As his serum calcium was found to be low he was given intravenous calcium chloride and the twitchings ceased. An intravenous transfusion of glucose water was started pre-operatively.

Under general anaesthesia an incision was made around the protuberant umbilical mass. The underlying tissues were dissected until a loop of bowel was seen which was constricted by a defect in the linea alba. The bowel was congested, but was considered to be viable. The constricting ring was divided, following which there was a gush of fluid from the peritoneal cavity. The child's condition rapidly deteriorated and he died a few minutes later. No cause for the sudden collapse and death was found at necropsy.

\section{CASE 2}

A boy, who had been born three months prematurely, was seen as an out-patient when he was 3 months old on account of umbilical and right-sided inguinal hernias. Adhesive strapping was applied to the umbilical hernia, but it is not known how long this was maintained. It was proposed to repair the inguinal hernia when he was older.

Two months later, however, he was admitted to hospital as an emergency because for nine days he had been having attacks of screaming during which he drew up his legs, and his mother noticed that the umbilical swelling had increased in size and had become bluish in colour. The baby had vomited a little and had been constipated.

On examination his general condition was very good and he weighed $12 \frac{3}{4} \mathrm{lb}$. $(5.8 \mathrm{~kg}$.). There was a large bluish protrusion at the umbilicus which could not be reduced. The inguinal hernia was easily reducible.

An operation was performed at once, and the hernial sac was found to contain a loop of very oedematous but viable bowel and a mass of omentum in which there was a haematoma. The obstruction was relieved and the baby made a rapid recovery.

Two weeks later he was readmitted because the inguinal hernia had become incarcerated. This was successfully relieved by operation.

\section{COMMENT}

In Case 1 there was presumably a congenital weakness of the umbilical scar, and raised intra-abdominal pressure, due to the large accumulation of ascitic fluid, resulted in herniation through the scar. The natural tendency for this type of hernia to resolve spontaneously in children (Woods, 1953) would also be unlikely to occur because of the constant increase of pressure in the abdomen. Local distension of the loop of bowel in the hernia, or adhesions due to the many paracenteses, may have been the factors precipitating the strangulation. No cause for the sudden collapse and death of the patient was evident at necropsy, but it may have been due to the sudden release of fluid from the peritoneal cavity.

The umbilical hernia of Case 2 was the usual infantile type, and there appeared to be no factor precipitating the strangulation.

It has been shown that adhesive strapping hastens the resolution of large umbilical hernias (Haworth, 1956), and the fact that strangulation does very rarely occur is perhaps an additional reason for strapping these cases.

Case 1 was admitted under the care of Mr. R. B. Zachary and Case 2 under Mr. W. J. Lytle, to both of whom I am grateful for permission to publish.

J. C. Haworth, M.B., M.R.C.P., D.C.H., Senior Medical Registrar, The Children's Hospital, Sheffield.

REFERENCES

Browne, D. (1952). British Medical Journal, 2, 1144. Crump. E P. (1952). J. Pediat., 40, 214. Haworth, J. C (1956). British Medical Journal, 1, 1286. MacLean, A. B. (1950). Brit. J. Surg.. 38, 239. Miller. R. H. (1932). New Engl. J. Med., 206. 389 Strange, S. L. (1956). Postgrad. med. J., 32, 39. Woods, G. E. (1953). Arch. Dis. Childh., 28, 450. 